\title{
RESORCIN POISONING
}

\author{
BY \\ A. A. CUNNINGHAM \\ From the Paediatric Unit, Kingston Hospital, Surrey
}

(RECEIVED FOR PUBLICATION JANUARY 13, 1956)

Resorcin poisoning in young children is rare but has been reported on a number of occasions, especially in the German literature. Nothen (1908) described poisoning in an 11-day-old child, suffering from pemphigus neonatorum, who was found dead in bed some hours after the application of $3 \%$ resorcin vaseline.

Kyrle (1915), in the course of treatment of a 2-year-old boy with eczema prescribed $10 \%$ resorcin lotion, and after two applications, at an interval of about 12 hours, the child's urine was noticed to be dark olive green on standing. His condition deteriorated rapidly, and when examined in hospital he was found to be cold, grey and cyanosed with a weak, irregular pulse. The pupils were dilated and there were mild, recurrent clonic fits involving the face and upper limbs. Within 12 hours the condition improved, the drowsiness and cyanosis diminished, but he developed a severe urticaria with raised temperature and severe dyspnoea requiring oxygen therapy. He made a gradual recovery. This case was interesting, because the resorcin lotion was applied to nearly intact skin.

Feigl (1918) described a 2-month-old child, suffering from generalized eczema, which had been treated with resorcin cream (concentration not mentioned). After three days the child became desperately ill, developed convulsions and died quickly.

Connerth (1925) had a patient $1 \frac{1}{2}$ years old with extensive eczema of the face and head, first treated with boric lotion and then with $5 \%$ resorcin zinc paste. After a few days the patient became drowsy, cyanosed and very ill, refusing all food. The haemoglobin fell to $45 \%$ and there was associated haemoglobinaemia and haemoglobinuria. The child died in convulsions.

Marie Haenelt (1925) treated a 3-week-old patient with napkin dermatitis using $5 \%$ resorcin vaseline. On the evening of the same day the baby was very restless, and next morning on admission to hospital was greenish-grey with severe cyanosis of the body generally. The urine was burgundy coloured, the blood was dark, with a haemoglobin of $53 \%, 2,900,000$ R.B.C.s per c.mm. and bilirubin $2.8 \mathrm{mg} . \%$. The child deteriorated rapidly and died within two days. The main postmortem findings were haemorrhages in the pleura and pericardium, a sepia-coloured liver on section and an enlarged spleen. Death was due to methaemoglobinaemia.

In Becker's patient (1933) a child, aged 42 days, suffering from extensive intertriginous eczema, treated with resorcin paste $2 \%$ on one occasion only, there was vomiting with the development of an intense petechial skin eruption with the passage of dark coloured urine. There was general drowsiness, the haemoglobin fell in two days from $65 \%$ to $14 \%$ and the R.B.C.s from $4,000,000$ to $1,000,000$ per c.mm. The child died on the fifth day in spite of treatment with blood transfusion.

In the course of the treatment for an extensive intertriginous eczema in the genital area of a child aged 36 days, Liebenam (1935) prescribed resorcin paste. This was applied moderately thickly five to six times within 24 hours, and the next day the child became gravely ill, with a greenish-grey skin and intense general cyanosis. The child became unconscious with opisthotonos and a rapid respiration rate, the haemoglobin fell to $65 \%$, and efforts to give blood intravenously were unsuccessful. The child died in convulsions two days after admission.

Wirth (1938) recorded a baby girl, $2 \frac{1}{2}$ months old, who, following treatment for diarrhoea, was admitted with restlessness and marked general cyanosis. The abdomen was tender and the liver and spleen were enlarged. The urine was yellowishgreen. The haemoglobin was $84 \%$ and the blood serum had a dirty, dark chocolate appearance. There was a suspicion of poisoning, and the medicine which had been given for the diarrhoea was sent for analysis. The baby was treated with blood transfusion and given oxygen, but in spite of this the haemoglobin fell to $62 \%$ in the days following admission. The child then made a quick recovery, and was discharged on the twelfth day, apparently 
quite well. Analysis of the medicine prescribed for the diarrhoea showed that it contained resorcin, which in error had been made up one hundred times too strong. The baby had had in all six teaspoonsful, equal to 150 centigrammes of resorcin.

Resorcin was proved by Bull and Fraser (1950) to have a definite anti-thyroid effect when administered parenterally. They described three cases in adults where myxoedema had followed prolonged application of resorcin ointment to varicose ulcers. The radioactive urinary iodine excretion tests in both cases showed an extremely low excretion, and an avid uptake by the thyroid gland. One of the patients had severe anaemia with a history of jaundice on two occasions, episodes suggesting haemolytic anaemia. Hart and Maclagan (1951) reported similar myxoedematous symptoms in an adult case with extensive varicose ulcers.

Owing to the rarity of the condition and its possible tragic results, the following case appears worthy of record.

\section{Case Report}

A baby boy, D.W., aged 7 weeks, was admitted to Kingston Hospital on March 4, 1953. He was born on January 15, after a normal delivery, birth weight $6 \mathrm{lb}$. $11 \frac{1}{2} \mathrm{oz}$. $(3,047 \mathrm{~g}$.). The neonatal period was uneventful apart from slight conjunctivitis, which responded to penicillin locally applied. Breast feeding was easily established. Between February 6 and 20 the mother suffered from severe abdominal colic without diarrhoea or vomiting, and was treated medically by her family doctor. During this time the baby developed green and slimy motions, but continued to take the breast milk satisfactorily. There developed, however, a marked inflammation of the skin of the buttocks, scrotum and neighbouring parts, and when the baby attended the Infant Welfare Clinic on February 20 a bland ointment was prescribed. By February 27 there was no improvement, and by then the skin had broken down extensively over the napkin area. Calamine lotion was prescribed and applied for four days. On March 3 the motions had returned to normal, but the raw skin persisted. A new ointment was prescribed with instructions for it to be applied to the napkin area after bathing the inflamed parts with warm water. This ointment was applied on four occasions only, the last one between 9 a.m. and $10 \mathrm{a} . \mathrm{m}$. on March 4 . The mother noticed after the fourth application that the child shivered all over for about a minute, and in the belief that he had caught cold in the bath, dressed him quickly. This episode did not worry her unduly at the time as the baby generally had a poor circulation. Afterwards he took the 10 a.m. feed quite well and was placed in the pram. Throughout the morning he whimpered more than usual, but when seen at 11.30 a.m. approximately, was asleep and seemed to be all right. Between 1 and 2 p.m. the mother noticed a peculiar deep blue discoloration of the lips, eyelids and skin, with a yellowish colour intermingled.
She called her neighbour, who nursed the baby for a time, ascribing the trouble to 'wind'. He improved a little, but refused part of the 2 p.m. feed, and when afterwards his condition deteriorated rapidly the mother brought him directly to hospital, where he was admitted at 3.30 p.m.

On examination the child was very ill with an intense, dusky-grey cyanosis and rapid, grunting respirations. There was no stridor and no intercostal recession (temperature $98 \cdot 8^{\circ} \mathrm{F}$., pulse 144 to 150 per minute, respiration 40 per minute).

The mouth and throat were clear, except for dusky cyanosis of the mucous membrane. The pulse was rapid, but no other abnormality was noted in the cardiovascular system. Respirations were rapid, but there was no evidence of pneumonia. The abdomen and central nervous system appeared normal.

There was an extensive dermatitis covering the whole napkin area, the rash having a purplish colour in line with the rest of the skin of the body and mucous membranes. There was marked oedema of the shaft of the penis. There was a scattered maculo-papular eruption of the lower buttocks, arms and forearms.

The urine was scanty, but a small amount obtained for examination was of port-wine colour and contained blood on routine ward testing.

A diagnosis of haemolytic anaemia with haemoglobinuria was made, and blood findings were: $\mathrm{Hb}$ (?) $80^{\circ}$ (serum turbid and coloured), R.B.C. 4,000,000 per c.mm., W.B.C. 36,000 per c.mm. A blood transfusion was set up using group $\mathrm{O}, \mathrm{Rh}$-negative blood, but after $50 \mathrm{ml}$. had been given it was discontinued.

During the next day the child remained dangerously ill (temperature $100^{\circ}$ F., pulse 160 per minute, respirations $\mathbf{4 0}$ per minute).

The $\mathrm{Hb}$ at 11.30 a.m. was $64^{\circ}$ o approximately (serum highly coloured and turbid), W.B.C. 40,000 per c.mm. (polymorphs $47^{\circ}$, lymphocytes $47^{\circ}$, monocytes $5^{\circ}$, eosinophils $1^{\circ}$ ). Blood transfusion was restarted, and $250 \mathrm{ml}$. of group $\mathrm{O} \mathrm{Rh}$-negative blood given. At 3 p.m. (with blood transfusion in progress) $\mathrm{Hb}$ was (?) $40^{\circ}$, R.B.C. $2,100,000$, W.B.C. 36,000 , platelets 300,000 per c.mm. The fragility of red cells was within normal limits.

The dermatitis was treated with calamine lotion and penicillin was administered parenterally.

On March 6 the child remained very ill, but if anything there was a slight improvement (temperature $101 \cdot 6^{\circ} \mathrm{F}$., pulse 150 per minute, respirations 40 per minute). The cyanosis of the mucous membranes and limbs was less intense. The papular eruption had spread to the abdomen, and there was a fresh outcrop of lesions on the arms and forearms. The spleen became easily palpable. The urine was thick, dark brown, with a greenish deposit. The blood serum was reddish-brown.

At 8 p.m., as the child did not have evidence of a severe infection and as the cause of the haemolytic anaemia was not apparent, I had a personal interview with the mother, when she was asked to bring up all the medicines and ointments which she and the child had had. She exactly repeated the history as originally told, and reaffirmed that she herself had only had medicine from 
her doctor for colic. One of the ointments which she produced had been dispensed by a local pharmacist on a prescription from the Infant Welfare Clinic and could not immediately be identified. This was the last ointment prescribed by the Clinic and applied on four occasions.

In the morning the hospital chief pharmacist, in consultation with the retail pharmacist by whom the ointment had been dispensed, discovered that he ointment was in fact unguentum resorcin B.P. In all 2 to 3 drachms had been removed, and this had presumably been applied to the affected area of skin. As unguentum resorcin B.P. contains $12 \cdot 5^{\circ}$, resorcin in a base consisting of glycerine, wool fat and soft paraffin, the amount of resorcin used was between 15 and 20 grains. This evidence pointed to resorcin as the source of the haemolytic anaemia.

The biochemical report now stated that the blood serum was reddish-brown and on spectroscopy there was a band at 630 millimicrons typical of methaemoglobin. The urine was dark brown and slightly cloudy. Centrifugation caused the separation of a dark green amorphous deposit, with a dark brown, clear supernatant fluid, which on spectroscopy showed two bands of oxyhaemoglobin. Porphyrins were not present, nor reducing substance. Protein tests were strongly positive. Tests suggested that the brown colour was due partly to melanin and the green to oxidation products from phenols. The most likely cause was suggested to be poisoning from a coal-tar derivative.

The biochemical report confirmed the clinical findings, and a diagnosis of resorcin poisoning was confidently made.

On March 7 the $\mathrm{Hb}$ was $76^{\circ}$, temperature $99^{\circ} \mathrm{F}$., pulse 134 per minute, respirations 44 per minute. As the cyanosis became less marked the jaundice became more noticeable. The spleen was still palpable, but much smaller. The child still took feeds badly and had frequent loose motions, so parenteral fluid therapy by intravenous drip was necessary to maintain fluid balance.

Good progress was maintained on March 8. Feeds were taken quite well. The diarrhoea had ceased. The haemoglobin, however, had fallen again to $46^{\circ} \mathrm{o}$.

On March 9 the papular rash which had been noted on the arms and trunk became more extensive, covering the entire trunk, face, scalp and limbs. The napkin dermatitis was slow in healing, the raw, inflamed area showing little, if any, response to local treatment.

By March 11 the good general progress was maintained. Haemoglobin was $40^{\circ}$, R.B.C. $2,400,000$ per c.mm., and no methaemoglobin was detected on spectroscopy.

The urine was cloudy and faintly brownish with many greenish-brown casts. There was a trace of protein, and tests for phenols were positive. Urobilinogen was present but not in excess.

On March 12 a blood transfusion of $250 \mathrm{ml}$. of group $\mathrm{O}$, rhesus-negative blood was given.

By March 13 the rash on the body had become extensive and confluent with superficial scaling of a psoriasiform appearance. Penicillin therapy was discontinued.

On March 16 breast feeding was again satisfactorily instituted. Apart from the extensive papulo-squamous skin eruption the child was making good progress. On March 17 this was sustained, and the $\mathrm{Hb}$ was $74^{\circ}$, and no phenol derivatives were detected in the urine. The good progress was maintained, and by March 26 the skin was extensively desquamated as large patches fell away. The scalp remained one thick mass of crusts.

On March 31 the baby was discharged from in-patient treatment. The skin of the trunk had almost completely desquamated apart from a few resistant scaly areas. The napkin area had healed. Oily calamine was applied to the face and trunk, and zinc and castor oil ointment to the buttocks.

On April 4 the child, attending as an out-patient, looked well and the mucous membranes appeared healthy. No thyroid swelling was noted. The scalp continued to be one mass of thickened crusts. As olive oil and calamine treatment of the scalp was producing no effects, it was decided to discontinue all treatment. A course of iron therapy was started by mouth.

On August 19 the child was well. There was still a small area of scalp crusting, which had not completely healed. Most of the crusted masses had, separated satisfactorily. The mother found, however, that if she applied water to any part of the body it produced a rash as though the child had been burned. She therefore made no attempt to wash him, merely oiled the skin.

A later report showed that the child was very well, and apart from the skin being rather sensitive, there was no other abnormality.

\section{Comment}

The Divisional Medical Officer on enquiry reported that at the particular infant welfare clinic where this patient had been treated, resorcin ointment had been prescribed in only a few cases and then in small amounts for refractory skin lesions. Apart from the patient described, no other had experienced any known ill effect.

This case, together with reports from the literature, illustrates the danger of using resorcin, even in the weakest lotion or ointment, on the tender skin of babies and young children. Absorption may be intense and lethal where the skin is broken, but the ointment may also be absorbed and produce serious effects in sensitive subjects, even when the skin is almost intact. Resorcin ointment should not be used in the treatment of napkin dermatitis, eczema or other skin eruptions in childhood.

\section{Summary}

The literature on resorcin poisoning in infants and young children is reviewed. A case of severe haemolytic anaemia with haemoglobinuria and a generalized papulo-squamous eruption due to resorcin poisoning is described. 
I wish to acknowledge the valuable assistance of Dr. J. F. Lees, who with Sister J. Taylor and other members of the nursing staff of the children's ward, effectively carried out the detailed treatment. I record my thanks also to Dr. D. Stark Murray, Consultant Pathologist, and his staff for the various haematological and biochemical investigations, to Mr. A. G. Shaw, Chief Pharmacist, for his report on the offending ointment, and to Dr. J. W. Starkey, Divisional Medical Officer, North Central Division, Surrey County Council, REFERENCES

Becker, J. (1933). Samml. Vergiftungsf., 4, 7. Bull, G. M. and Fraser, R. (1950). Lancet, 1, 851

Connerth, O. (1925). Ż. Kinderheilk., 39, 628.

Feigl, J. (1918). Biochem. Z., 85, 171.

Haenelt, Marie (1925). Müch. med. Wschr., 72, 386.

Hart, F. Dudley and Maclagan, N. F. (1951). Lancet, 1. 530.

Kyrle, J. (1915). Derm. Z., 22, 505.

Liebenam, L. (1935). Med. Welt, 9, 1217.

Nothen, H. (1908). Med. Klin., 4, 901.

Wirth, J. (1938). Kinderärtztl. Prax., 9, 150. for his cooperation. 